\title{
Underground roadway design considerations for efficient autonomous hauling
}

\author{
RJ Thompson Curtin University Western Australian School of Mines, Australia \\ H Malekzehtab Curtin University, Australia
}

\begin{abstract}
Whilst considerable time and effort is expended on loader and truck haulage system selection and optimisation for an underground operation, comparatively less effort is applied when considering the design and maintenance management of the roadways on which the system is intended to operate. These roadways or declines should be considered an asset, and should, in conjunction with the vehicles using them, be optimally designed and their routine maintenance predicted, planned and managed accordingly. Ad hoc or empirical approaches to roadway design are generally unsatisfactory because of the potential for either overdesign or specification of short-term low-volume roads, or conversely and more typically, underdesign leading to excessive operating and road maintenance costs, premature failure and significant safety and productivity impacts.

The interaction of the truck or loader with the roadway running surface will directly influence the productivity, cost efficiency, and critically, safety of the system as a whole. This is true for both manual and autonomous operations. However, with autonomous systems, the roadway itself becomes all the more critical to the success of these type of operations; not only in relation to mine operators' requirements for safer and more efficient and predictable haulage systems, but also in response to autonomous vehicle manufacturers' requirements for a more predictable and controlled operating environment.

This paper presents a brief summary of fundamental roadway design concepts, followed by a review of current approaches to underground roadway design, from both structural (layerworks) and wearing course (running surface) perspectives. The design and technological challenges associated with providing a safe, predictable and affordable roadway for autonomous underground mine vehicles is then examined as a basis for evaluating the contributions that engineered roadway design and management can deliver to large-scale bulk and autonomous underground mining operations.
\end{abstract}

Keywords: roadway design, decline, pavement design, hauling, underground mining, autonomous

\section{Introduction}

Most large-scale underground and bulk mining methods rely on ore and waste transfer using rubber-tyred vehicles; most commonly load-haul-dump (LHD) or scooptram units, running from the drawpoint or extraction point to an orepass or transfer. Where a decline has been designed and is used to bring the ore and waste to surface, purpose built underground haul trucks are operated in these excavations. Both applications require the design and management of roadway infrastructures to support safe and cost-efficient haulage. These roadways, be they oredrives (extraction), footwall drives, ring drives or main declines should be considered an asset and should, in conjunction with the vehicles using them, be optimally designed and their routine maintenance planned and managed accordingly.

Loader and truck haulage system selection and optimisation for an underground operation is well documented and defined. However, comparatively little information is available to the mining or planning engineer regarding the design and operation of the roadways on which the system is intended to travel. Whilst many concepts from highway engineering can be adapted to the design, construction and management of mine roadways, there are significant differences in applied loads, traffic volumes, 
construction material quality and availability, together with design life and road user cost, safety and affordability considerations. Table 1 summarises the key differences in road design requirements between surface (public) roads, surface (mine haul) roads and underground roadways.

Table 1 Key differences in design and provision of public and mine (surface and underground) roads

\begin{tabular}{|c|c|c|c|}
\hline Characteristic & $\begin{array}{l}\text { Underground mine } \\
\text { roadway }\end{array}$ & $\begin{array}{l}\text { Surface mine haul } \\
\text { road }\end{array}$ & $\begin{array}{l}\text { Public } \\
\text { road/highway }\end{array}$ \\
\hline Design life (YR) & $10>Y R>1$ & $20>Y R>0.5$ & $\mathrm{YR}>30$ \\
\hline Traffic volume ${ }^{a}$ & $10^{4-5}$ & $10^{4-5}$ & $10^{7-8}$ \\
\hline Equivalent traffic volume ${ }^{b}$ & $10^{7-9}$ & $10^{8-11}$ & $10^{6-8}$ \\
\hline Traffic axle loads (t) & $20-60$ & $200-400$ & $<10$ \\
\hline Traffic speeds (km/hr) & $<45$ & $<55$ & $<110$ \\
\hline Tyres pressures & Up to $1,000 \mathrm{kPa}$ & Up to $760 \mathrm{kPa}$ & Up to $830 \mathrm{kPa}$ \\
\hline Subgrade & Rock & Rock or soils & Soils \\
\hline \multirow[t]{2}{*}{ Material sources } & $\begin{array}{l}\text { Crushed and screened } \\
\text { waste rock }\end{array}$ & $\begin{array}{l}\text { Waste rock or borrow } \\
\text { pit material }\end{array}$ & \multirow{2}{*}{$\begin{array}{l}\text { Borrow pit material } \\
\text { Road standard } \\
\text { aggregate }\end{array}$} \\
\hline & $\begin{array}{l}\text { Road standard } \\
\text { aggregate for } \\
\text { bitumen, concrete or } \\
\text { hybrid stabilised road }\end{array}$ & $\begin{array}{l}\text { Crushed and screened } \\
\text { waste rock }\end{array}$ & \\
\hline \multirow[t]{2}{*}{ Cost to construct } & $\begin{array}{l}\text { High - material } \\
\text { preparation and } \\
\text { transport costs }\end{array}$ & $\begin{array}{l}\text { High - material } \\
\text { preparation and } \\
\text { volumes required }\end{array}$ & $\begin{array}{l}\text { Varies with design } \\
\text { and availability of } \\
\text { material }\end{array}$ \\
\hline & $\begin{array}{l}\text { Met by road user } \\
\text { (mine) }\end{array}$ & $\begin{array}{l}\text { Met by road user } \\
\text { (mine) }\end{array}$ & $\begin{array}{l}\text { Met by local roads } \\
\text { authority }\end{array}$ \\
\hline $\begin{array}{l}\text { Cost to maintain and } \\
\text { rehabilitate }\end{array}$ & $\begin{array}{l}\text { Met by road user } \\
\text { (mine) }\end{array}$ & $\begin{array}{l}\text { Met by road user } \\
\text { (mine) }\end{array}$ & $\begin{array}{l}\text { Met by local roads } \\
\text { authority }\end{array}$ \\
\hline $\begin{array}{l}\text { Vehicle operating costs } \\
\text { (fuel, tyres, operator, } \\
\text { maintenance and repairs) }\end{array}$ & Road user (mine) & Road user (mine) & Road user (public) \\
\hline Maximum gradient (slope) & $15 \%$ & $10 \%$ & $\begin{array}{l}12 \% \text { (for limited } \\
\text { length usually) }\end{array}$ \\
\hline Water damage risk & $\begin{array}{l}\text { High - generally wet } \\
\text { environment }\end{array}$ & $\begin{array}{l}\text { Medium - depends } \\
\text { on environment }\end{array}$ & $\begin{array}{l}\text { Med-low-depends } \\
\text { on environment }\end{array}$ \\
\hline Integrated design level ${ }^{c}$ & High & High & Variable with design \\
\hline \multicolumn{4}{|l|}{ Notes } \\
\hline \multicolumn{4}{|c|}{ a Traffic volumes based on vehicle repetitions over life of road. } \\
\hline \multicolumn{4}{|c|}{$\begin{array}{l}\text { b Traffic volumes based on an 'equivalent design axle' concept. Large heavy equipment repetitions are } \\
\text { converted into a number of (smaller) 'equivalent standard axle' (ESA) loadings, to equate heavy vehicle traffic } \\
\text { volumes to an increased number of standard axles. However, mine vehicle axle loadings significantly exceed } \\
\text { 'heavy' vehicle axle loadings and ESA methodology can't be universally applied. }\end{array}$} \\
\hline \multicolumn{4}{|c|}{$\begin{array}{l}{ }^{c} \text { Considering additional factors in the design procedure such as available height for pavement structure, limited } \\
\text { dimensions for construction machinery, utilities, drainage and safety considerations. }\end{array}$} \\
\hline
\end{tabular}


This indicates that a custom-made design solution is required for underground roadways. Without attention to the unique design requirements of these roadways, an ad hoc or empirical approach to roadway design will usually be unsatisfactory because of the potential for either overdesign and specification of short-term low-volume roads, or conversely and more typically, underdesign leading to excessive operating and road maintenance costs, premature failure and significant safety and productivity impacts (Asphalt Institute 2013; Seedsman et al. 1994).

Historically, underground roadway construction was based on a crushed waste rock product (often $<50 \mathrm{~mm}$ in size with much of the fines or $<2 \mathrm{~mm}$ fractions removed), supplied from a surface crushing installation (Caterpillar n.d; Carrick et al. n.d). The roadway would be laid in a single 150-450 mm lift (with variation in thickness to accommodate undulations in the blasted floor profile and prevent point loading up into the pavement), shaped to profile with a grader and, ideally, compacted with purpose built underground construction equipment. This process created a more even running surface above the irregular blasted floor (or blasted rock fines) in the tunnel and for low traffic volumes and lighter axle loadings, was generally fit-for-purpose except under the most arduous circumstances or where poor drainage and ponding of water occurred. However, with the advent of much larger load and haul units, coupled with faster haulage and autonomous operation, this empirical design approach is inadequate for today's large-scale bulk mining operations (Caterpillar n.d.). As is shown schematically in Figure 1, increasing wheel loads and stresses (or conversely, too thin a 'structure') subjects the materials comprising the roadway to higher levels of stress and strain, which, in many cases, is well beyond the capability of the material to support. Thus, road performance will be compromised as the materials fail in service (typically seen as potholing, rutting and subsequent deterioration and rapid abrasion of the running surface). Depending on the design adopted, in addition to the analysis of stresses and strains in a road, there are various other design criteria that can be used to assess the suitability of specific materials when combined into a roadway design.

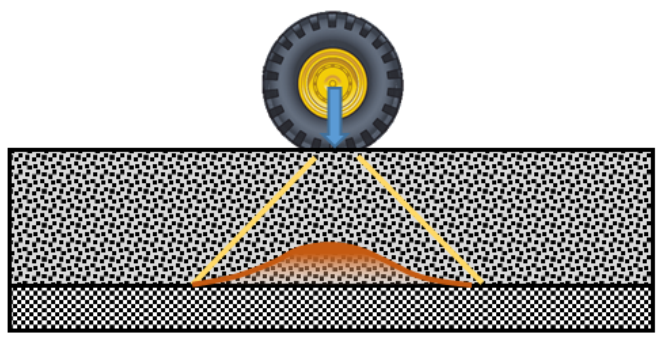

Small wheel loads and associated stress distribution

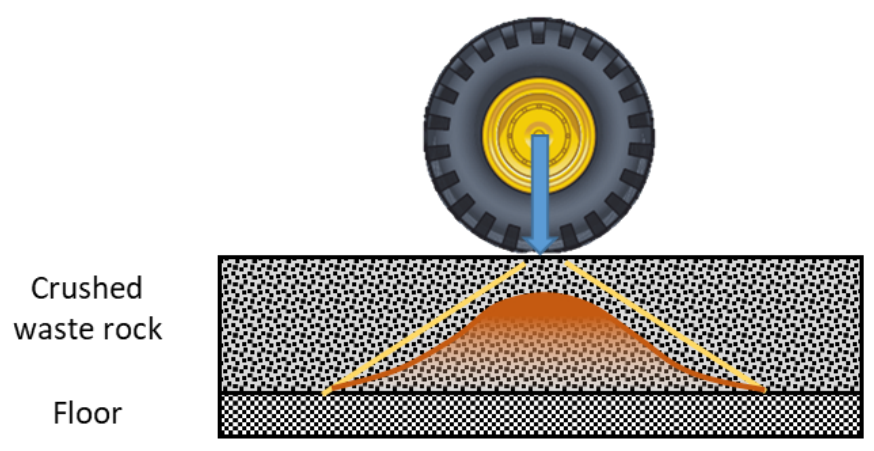

Large wheel loads and associated stress distribution

Figure 1 Schematic representation of stress distribution under small and large wheel loads

Many modern bulk mining operations have realised the benefits of improved roadway design and in several cases have adopted and developed either bituminous, high-strength ( $80 \mathrm{MPa})$ concrete or hybrid stabilisation treatments and road design methodologies to mitigate many of the road 'defects' referred to above. These approaches address, in particular, the effects of roadway deterioration (especially potholing, rutting and tyre abrasion of the running surface), tyre wear, machine and operator fatigue, and directly influence the productivity, cost-efficiency and, critically, safety of the system as a whole (both manual and autonomous). Furthermore, as loaders and trucks increase in size and payload, roadway performance can be compromised, resulting in excessive total road user costs; often seen directly as an increase in cost per tonne hauled, but also indirectly as reduced production rates, reduced availability, and vehicle and component service life.

With autonomous haulage systems (AHS), the roadway performance requirements become all the more critical to the success of these types of operations; not only in relation to mine operators' requirements for safer and more efficient and predictable haulage systems, but also in response to autonomous vehicle manufacturer requirements for a more predictable and controlled operating environment. With autonomous trucking or LHDs, vehicle path wander is minimal and the roadway will be subject to highly channelised wheel 
loads over a very limited area, without the wheel path variations often encountered in conventional load and haul systems. Running surface tolerances for autonomous vehicles are typically within $\pm 100 \mathrm{~mm}$, and sudden vertical movements (e.g. from a pothole or crossing a rut in the roadway) that exceed the set tolerance would bring the machine to a stop. With manned equipment, operator fatigue, whole body vibration and soft tissue injuries would similarly impact productivity (Wolfgang \& Burgess-Limerick 2014). Thus, the operating performance of the mines' roadways is mission critical to the overall success of both conventional and autonomous large-scale bulk mining applications. Rapid deterioration in road performance will require costly remediation, human intervention and significant, albeit temporary, changes to operating procedures to accommodate these types of events.

This paper presents a brief summary of pavement design concepts, following which the flexible pavement approach to underground roadway design is introduced, both from a structural (layerworks) and wearing course (running surface) perspective. The design and technological challenges associated with providing a safe, predictable and affordable roadway for autonomous underground mine vehicles is then examined, from both rigid and flexible design alternatives, as a basis for evaluating the contributions that engineered roadway design and management can deliver to conventional and autonomous underground bulk mining operations.

\section{Fundamental concepts in road design}

Some of the earliest road builders were the Romans, who developed sophisticated stone-paved and metaled roads (the 'via munita'), as well as other designs ('via glareata' - gravel surfaced) and 'via terrena' (flattened earth) roads. Each design had a specific purpose, life and traffic in mind, and whilst the philosophy of provision, materials and methods used for road construction then would still be recognisable today, design concepts have progressed considerably in terms of advancements in materials and their performance characterisation, prediction and application.

A road comprises a number of recognised layers (courses), each with a specific function in the overall design. Progressing from the top down, road vehicles interact with the wearing course or surfacing, which is either classed as 'paved' (e.g. Portland cement concrete, asphalt, bitumen, etc.) or 'unpaved' (i.e. a natural or treated/selected gravel-surfaced road). Below the wearing course are the structural layers, typically base and sub-base, which both support the wearing course and protect the material below the road from traffic-induced loading. The material below the road is the subgrade material (either fill or in situ), and it is often this material which is significantly weaker than the layerworks above, and as such is the source of many road performance problems if not correctly addressed in the design stage.

The composition of the layerworks that provide structural support for the road vary, dependant on design requirements and material availability and cost. These underlying layers may include gravel, crushed stone aggregate or subgrade itself, with or without treatment (stabilisation - typically cement-, asphalt-, lime- or polymer emulsion-treated for additional strength and support). This is often the case where either road-building material costs are high or the material required to increase the structural capacity of the layers is not locally available.

Two main categories of road design are recognised; either a 'flexible' or 'rigid' design, and are described below and compared in Table 2:

Flexible: A flexible design consists typically of three to four layers above subgrade. In these designs, the highest traffic-induced stress occurs at the surface and decreases with depth. In this 'balanced' design, highquality or high-strength materials are used in the top of the road, whilst lower-quality materials can be used as the depth of layerworks increases. It is considered a flexible road since layers are anticipated to deform slightly and then recover, as a load is applied. Over the long-term, with increasing traffic repetitions, these deformations become permanent, which will lead to wheel path rutting, potholing and other defects or distress, and eventual failure of the road. The design life of a flexible road is thus based on the layer strengths, thickness and estimates of the critical modes of failure and associated limits modified to meet the magnitude and number of traffic repetitions together with the required service life. 
Rigid: Ports, heavy vehicle terminals, industrial floors, airport hardstands and, increasingly, bulk mining operations are common examples of rigid designs. They are generally constructed in three layers; subgrade, sub-base/base (often treated) and a concrete slab. The concrete slab is dimensioned to control cracking behaviour in the slab through joint spacing considerations. Joint spacing is determined by the slab panel dimensions and overall, as with flexible designs, the layerworks distribute wheel loads so that the induced stresses in the subgrade do not cause permanent deformation. Commonly, jointed plain or reinforced concrete and/or continuously reinforced concrete pavements are used. Each has its own characteristics in terms of contraction joints, and at transverse joints, consideration is given to how load transfer is achieved across cracks or slabs. In underground operations, the philosophy of provision and performance is somewhat different in that medium-strength concrete is often used as a levelling layer (sub-base) between the solid floor (often excavated to 'solid' well below the designed floor level). Above that, a higher-strength concrete base is cast in situ above which pre-cast high-strength and wear-resistant panels are set.

Table 2 Comparison of key performance consideration of flexible and rigid pavements

\begin{tabular}{ll}
\hline Flexible pavement & Rigid pavement \\
\multicolumn{1}{c}{$\begin{array}{l}\text { Wearing } \\
\text { Base }\end{array}$} &
\end{tabular}




\section{$3 \quad$ Mine roadway design methodology}

The generic approach to road design, construction, operation and maintenance provides for safe and cost-effective transportation, but requires specific modifications and/or limitations to suit, or as constrained by end-user requirements. In the context of underground mine roadways, as alluded to earlier, these requirements are unique and can be associated with four distinct design components (Thompson 2011):

\section{Geometric design.}

2. Structural design.

3. Functional design.

4. Maintenance management system design.

These design components have been derived from the historically empirical approach to mine road design, wherein an operating road is often incrementally improved until a satisfactory standard of performance is achieved. The various design activities are best addressed using an integrated approach, where specific activities apply to each component of design and optimisation takes place during design, as opposed to the operational phase of the road. If one design component is deficient, this will often manifest as inherently unsafe, maintenance-intensive and high rolling resistance roads. This combination of circumstances translates into hazardous, high operating cost, low-productivity roadways. The cure, however, is not simply to increase routine roadway maintenance (blading/scraping) frequency - without recourse to road redesign and rehabilitation (complete overhaul), no amount of routine maintenance will fix a poorly designed roadway. Preferably, components of the road infrastructure design process must be correctly addressed and integrated with each other at the design stage, as illustrated in Figure 2.

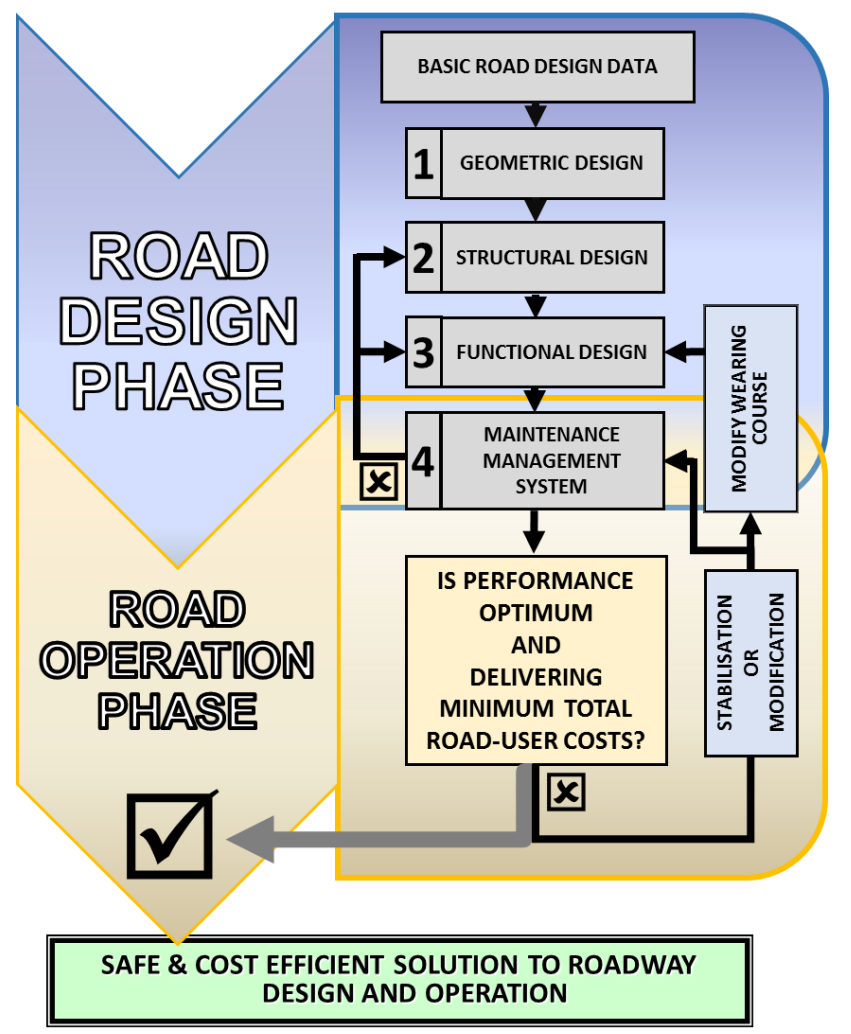

Figure 2 Typical mine roadway design methodology (modified after Thompson 2011)

As a precursor to describing the design and technology challenges associated providing a safe, predictable and affordable roadway for conventional or autonomous underground vehicles, the broad design requirements are described. 


\subsection{Geometric design}

Commonly, this is the starting point for any roadway design and refers to the dimensions, layout and alignment of a roadway, in both the horizontal and vertical plane. Key considerations are equipment size, mine services, drainage and ventilation. From an equipment perspective, geometry should consider gradeability, sight and stopping distances (more so where speeds are high), intersection design, curves and switchback radius, together with transitions between vertical alignments and the accommodation of drainage and sumps. The ultimate aim is to produce an optimally efficient and safe geometric design - but this has to be tempered with the mine, orebody and associated geotechnical constraints, and compromise is often necessary where roadway geometric requirements conflict with mining constraints.

\subsection{Structural design}

The structure or layerworks provides roadway 'strength' to carry the imposed loads over the design life of the road without excessive deformation of one or more layers in the road. With underground roads, this is often seen as a result of a layer of relatively weak material sandwiched between the solid tunnel floor and a strong base or wearing course. Commonly, it is the low-strength, moisture-sensitive 'muddy' material that remains after blasting and mucking.

The various layers comprising the roadway structure should be designed according to their strength and assessed against design limits related to the specific type of layer used and its mode of failure. Various structural design criteria are used throughout the world, both for flexible and rigid designs, the majority of which have been developed for conventional road and highway design. In the case of mine roadway design, several issues preclude the direct adoption of these existing methodologies, as was shown in Table 1. Furthermore, significantly, no direct relationships can be inferred between assumed modes of roadway failure at the magnitude of loading applied by standard axle loading and those of mine vehicles.

In a flexible roadway design methodology, each layer in a structural design, dependant on its characteristics, has a design limit (be it shear strength, tensile strain, compressive strain, compressive, tensile or flexural stress, etc.). In conventional road design, all vehicles are converted to an ESA through the use of a damage exponent, to calculate the design traffic volume or repetitions to failure (i.e. the 'life' of the road), such that the higher axle loadings represent more ESA repetitions. The damage exponent itself is related to the structural design and can vary from three (granular layer over cemented layer) to in excess of seven (cemented pre-cracked layer over granular layer) (Committee of State Road Authorities (CSRA) 1996; Theyse et al. 1996).

Using a typical $63 \mathrm{t}$ capacity underground truck as an example, when considering ESAs for this vehicle, a production target of 2 Mtpa equates to 87 truck repetitions per day, or nearly 159,000 over the five-year design life of the roadway. However, if the ESA concept were applied, together with a damage exponent of three (to replicate a layer of crushed rock above the tunnel floor), a design would be required for in excess of 102 million ESAs. In this case, and assuming the same layerworks strength factors apply, the design would require a minimum Factor of Safety against shear failure in the granular layer of 1.74 . Similarly, vertical compressive strains in the top of these types of layers would have to be limited to under 675 microstrains $(0.675 \mathrm{~mm} / \mathrm{m})$ in order to achieve the required design life of the roadway. Critically though, this approach assumes that the mode of failure remains unchanged between an $80 \mathrm{kN}$ axle loading and that of a $600 \mathrm{kN}$ axle loading - the equal deflection (stress) equal damage criterion, which is known to be unreliable at the levels of wheel loading generated by mine vehicles, port stackers and other high wheel load design applications (Yoder \& Witzak 1975; Thompson \& Visser 1996; Pidwerbesky 2004).

\subsubsection{Mechanistic structural design - flexible underground roadways}

Using the truck and traffic volume described previously, a mechanistic approach to the structural design of a flexible roadway is analysed and measured against appropriate limiting design criteria to determine its suitability to the application, in which individual layers in the roadway are characterised by their resilient modulus ( $E_{\text {eff }}$ ) and Poisson's ratio $(v)$, and subject to specific wheel loadings and contact stresses (for a typical 
63 t capacity underground truck) over the (variable) thicknesses of each layer. In Figures 3 and 4, four roadway design options have been analysed using the South African Mechanistic Design Methodology layerworks materials' descriptors and design parameters (CSRA 1996):

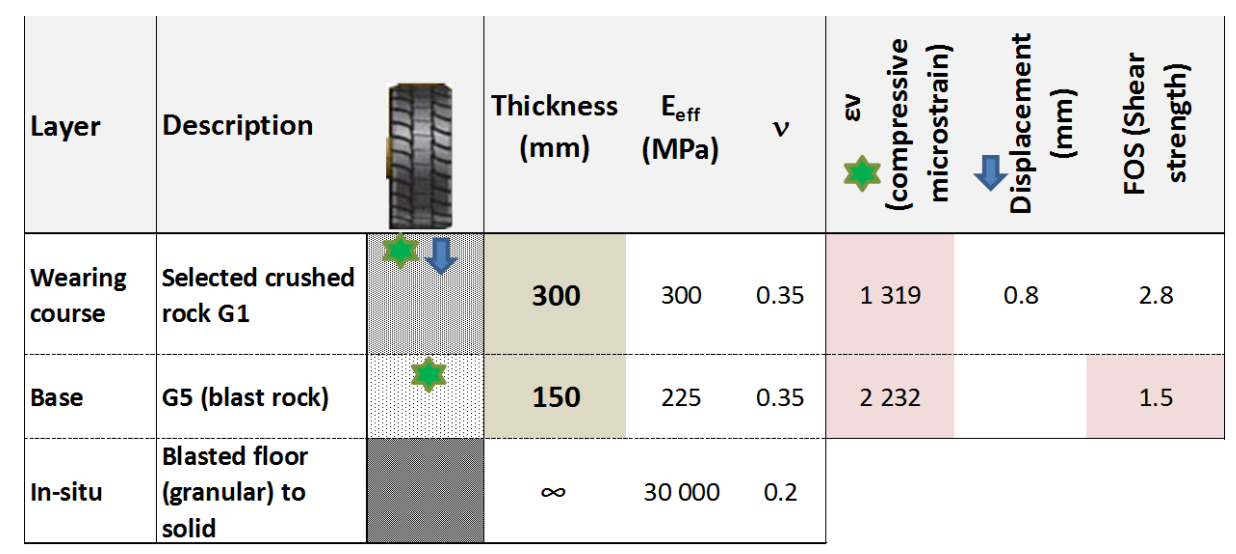

(a)

\begin{tabular}{|c|c|c|c|c|c|c|c|c|}
\hline Layer & Description & Bif & $\begin{array}{c}\text { Thickness } \\
\text { (mm) }\end{array}$ & $\begin{array}{c}E_{\text {eff }} \\
(\mathrm{MPa})\end{array}$ & $v$ & 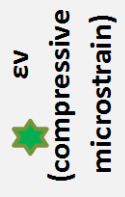 & 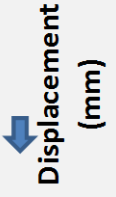 & 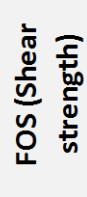 \\
\hline $\begin{array}{l}\text { Wearing } \\
\text { course }\end{array}$ & $\begin{array}{l}\text { Selected crushed } \\
\text { rock G1 }\end{array}$ & & 300 & 300 & 0.35 & 1545 & 0.5 & 3.4 \\
\hline Base & Selected DR & & 150 & 1800 & 0.35 & 312 & & 2.9 \\
\hline In-situ & $\begin{array}{l}\text { Blasted floor } \\
\text { (granular) to } \\
\text { solid }\end{array}$ & & $\infty$ & 30000 & 0.2 & & & \\
\hline
\end{tabular}

(b)

Figure 3 Mechanistic structural design of mine roadways. (a) Case 1; and, (b) Case 2

Case 1: In this case, some very poor quality material has been left on the floor of the tunnel (150 mm G5), typical of blast fines. Even with a much better quality selected crushed rock (G1) of $300 \mathrm{~mm}$ placed on top, the roadway nevertheless shows low Factors of Safety (FOS) against shear failure in the layerworks and vertical compressive strains are excessive. To meet the design criteria, an excessively thick structure is required which is both impractical and which would be prohibitively expensive in terms of costs associated with material preparation, transport and construction. With a poor-quality, weak (and moisture-sensitive) layer sandwiched between two much stronger layers, most roadways are unlikely to meet design specifications or required levels of performance.

Case 2: In this case, the poor quality G5 on the floor of the tunnel has been removed and a $150 \mathrm{~mm}$ layer of selected dump rock (DR), typically $<50 \mathrm{~mm}$ (i.e. with a top size less than $50 \mathrm{~mm}$ ) and minimal fines (typically less than $20 \%$ finer than $2 \mathrm{~mm}$ ). This is an inherently stronger layer and is advantageous from a drainage perspective, as it prevents pore pressure development and seepage from reaching the uppermost layer in the design. With this modification, layerworks response is improved, but the high vertical compressive strains in the wearing course indicate eventual rutting and poor trafficability. In both design cases 1 and 2, the unbound nature of the $\mathrm{G} 1$ crushed rock layer means it is susceptible to water ingress, loss of fines, dustiness, ravelling and rutting. It would require frequent maintenance to counteract these effects. 


\begin{tabular}{|c|c|c|c|c|c|c|c|c|c|}
\hline Layer & Description & $\begin{array}{l}\text { Thickness } \\
\text { (mm) }\end{array}$ & $\begin{array}{c}E_{\text {eff }} \\
\text { (MPa) }\end{array}$ & $v$ & 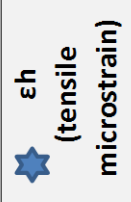 & 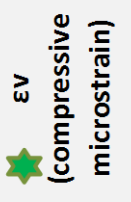 & 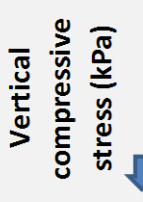 & 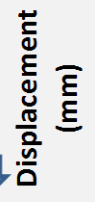 & 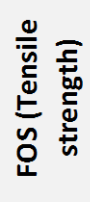 \\
\hline $\begin{array}{l}\text { Wearing } \\
\text { course }\end{array}$ & $\begin{array}{l}\text { Selected crushed } \\
\text { rock G1 + EBS + } \\
\text { cement }\end{array}$ & 150 & 600 & 0.3 & 50 & & 700 & 0.2 & 2.6 \\
\hline Base & Selected DR & 150 & 1800 & 0.35 & & 263 & & & \\
\hline In-situ & $\begin{array}{l}\text { Blasted floor } \\
\text { (granular) to } \\
\text { solid }\end{array}$ & $\infty$ & 30000 & 0.2 & & & & & \\
\hline
\end{tabular}

(a)

\begin{tabular}{|c|c|c|c|c|c|c|c|c|c|}
\hline Layer & Description & $\begin{array}{c}\text { Thickness } \\
(\mathrm{mm})\end{array}$ & $\begin{array}{c}E_{\text {eff }} \\
(\mathrm{MPa})\end{array}$ & $v$ & 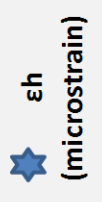 & 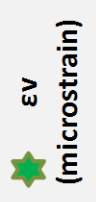 & 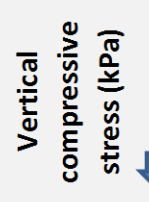 & 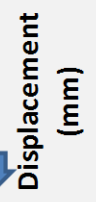 & 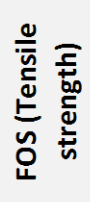 \\
\hline $\begin{array}{l}\text { Wearing } \\
\text { course }\end{array}$ & Densimac & 100 & 19500 & 0.2 & -0.5 & & 699 & 0.1 & - \\
\hline Base & RCC & 100 & 26000 & 0.2 & 27 & & & & 2.32 \\
\hline Sub-base & Selected DR & 150 & 1800 & 0.35 & & 226 & & & \\
\hline In-situ & $\begin{array}{l}\text { Blasted floor } \\
\text { (granular) to } \\
\text { solid }\end{array}$ & $\infty$ & & & & & & & \\
\hline
\end{tabular}

(b)

Figure 4 Mechanistic structural design of mine roadways. (a) Case 3; and, (b) Case 4

Case 3: In this case, design option 2 has been modified with the wearing courser layer, although still comprising G1 material, now combined with a nano-copolymer mix-in stabilisation and lightly cemented treatment (1\%) (Soil Solutions 2018). This layer is thus a hybrid flexible-rigid layer, which changes the mode of failure of the layer (although still semi-flexible) and thus the applicable design criteria. Importantly, the modification allows these design criteria to be met and the pavement design, although now only $300 \mathrm{~mm}$ in total thickness, to meet the design specifications. Further advantages accrue in terms of the conventional layerworks materials and construction technology used, as well as the low maintenance requirements of the hybrid wearing course, together with its ability to repel water, reduce fugitive dust emissions and a better response to the applied loads. However, it may nevertheless still be susceptible to the abrasive effects of tyres at the high contact stresses typical of the vehicles on the roadway.

Case 4: This case represents an alternative approach in which both the wearing course and the base are modified to better meet the design specifications. The wearing course and base together comprise a composite underground rapid application (CURA) roadway concept developed by Piran Mining Pty Ltd, (Australia), CBM and SBK (Sweden). The wearing course utilises a polymer-grout (Densiphalt, ITW Engineered Polymers 2018) in conjunction with a pervious (open-graded) concrete, to produce a high-strength macadam ('Densimac'), with a chemically bonded bauxite-ceramic wear-resistant surface armouring. The base is formed from a conventional layer of roller compacted concrete (RCC). RCC has similar strength properties and consists of the same basic ingredients as conventional concrete, but has different mixture proportions and a higher percentage of fine aggregates, which allows for tight packing, consolidation, strength and durability. Both layers are placed with a standard paver (equipped with a double pressure bar taming screed) and are followed by roller compaction, as with all the other designs cases. Although $50 \mathrm{~mm}$ thicker than case 3 , this design delivers a significantly enhanced response to the applied wheel loads and is ideally suited to high traffic volumes, higher contact stresses and high lateral loads (derived from low-speed articulated 
turning, typical of underground loaders at drawpoints and oredrives with a full load). In this application, it thus has a longer service life with virtually no maintenance requirements.

\subsection{Functional design}

Equally important as the structural strength of the design, is the functional trafficability of the roadway. This is dictated to a large degree through the selection, application and maintenance of the wearing course materials. The functional design can also significantly influence roadway structural strength too, since in many stabilised or hybrid applications, the wearing course gravels are not 'lost' during trafficking or due to environmental effects. However, the role of this layer from either of the functional or structural perspectives can be quite different. Wearing courses have historically been based on crushed hard rock material, but these unbound materials suffer from a number of key deficiencies; chiefly, loss of fines which can impact mine dewatering systems, poor ride quality (rutting, potholing, etc.), excessive dust, ravelling (loose material), abrasive wear, increased tyre wear and damage, and an accompanying loss of productivity. The result of these effects is seen as an increase in overall vehicle operating and road maintenance frequency and costs. For high-productivity mines, the aim is to build low- or no-maintenance roadways, and a key functional design requirement is thus the virtual elimination of regular road maintenance.

To meet these requirements, recent innovations in functional design include bituminous surfacing and high-strength concrete roadways, modified hybrid polymer stabilised or grouted and armoured materials in which high-quality crushed materials are used, subject to more rigorous grading, plasticity and strength controls. These improvements enhance both the functional performance requirements in addition to contributing significantly to the structural strength of the roadway and, critically, reduced surface deterioration eliminates the need for regular road maintenance. Two such examples which fulfil these criteria were introduced in the structural design case studies presented previously.

\subsection{Maintenance design}

The maintenance design predicts routine roadway maintenance requirements for each segment in an underground network of roadways, the majority of which will be subject to progressive deterioration, more so when the design criteria previously described are only partially met. In poorly designed roads, progressive deterioration (perceived as an increase in the degree and extent of road defects or distress) is rapid and maintenance can be planned and scheduled to arrest progressive deterioration, and to minimise total (vehicle operating and road maintenance) costs across the network. This approach is especially important where road maintenance assets are scarce and need to be used to best effect, to provide the greatest benefit from an investment in road maintenance in terms of improved haulage performance.

Practically, unlike surface roads where routine maintenance and traffic can be easily accommodated, underground roadways have to be closed to traffic to allow maintenance to be applied. This is especially problematic in high-tonnage bulk mining operations, as there are often no alternative roadways available and, more critically, the mining method often dictates where and at what rate ore must be mined, and any deviation from that schedule can lead to problems with cave progression, dilution or adverse geotechnical conditions. Thus, the low- or no-maintenance roadway is commonly the preferred option, and whilst technically feasible, given the short operating life of many roadways, economic justification on the basis of savings in road maintenance alone can be problematic. Ideally, a cost-optimisation approach should be adopted where the value invested in the roadway is offset against the costs of lost production, road maintenance and the associated reductions in vehicle availability, utilisation and operating life, and increased operating costs.

\section{$4 \quad$ Impacts of poor design on productivity}

The primary measure of mine roadway performance is often based on rolling resistance which, when combined with the road grade, is the total resistance a vehicle must overcome to move forward. Whilst roadway grade is fixed by mine geometry, rolling resistance is variable depending on the quality of the roadway design, build and materials used, together with the vehicle types and traffic volumes on the road. 
Rolling resistance occurs as a result of the deformation of the road's layerworks materials. In other instances, rolling resistance is also derived from the effects of wearing course distress and deterioration. In the case of unsuitable layerworks materials or design, the lack of support below the wearing course (even if it is in itself a well-selected wearing course) will result in rapid deterioration, leading to further increases in rolling resistance. Established models of rolling resistance progression indicate that it peaks at a specific value as drivers start to avoid poor sections of the road (Thompson \& Visser 2006). In the case of underground roadways, such avoidance activities are impractical, and in the case of autonomous operations, would not occur as the vehicles are guided by relative location on a fixed route, not by roadway condition.

All mine roadways will have a minimum amount of rolling resistance, even on the best designed, built and maintained road, typically 2 to $2.5 \%$, but in this case, resistance is primarily from tyre flexing as opposed to surface distress or layerworks deflection. With poorly designed roads, both sources combine to generate high rolling resistance - a problem that gets worse in the presence of water, which weakens construction materials further, leading to yet higher resistance. Accurately measuring, evaluating and modelling rolling resistance can be complicated, but the value of the information is high since it is rolling resistance that ultimately dictates how a mine's unit cost of haulage changes in response to roadway deterioration and its impact on productivity.

Rolling resistance itself is always working against us except in the context of a down grade haul and, in that case, it assists only from a truck retarding perspective. The factors that contribute to rolling resistance, even on a downgrade haul, indicate underlying road design, construction or road maintenance issues which would nevertheless adversely affect tyre and truck life, as well as truck maintenance and repair costs too.

Using a typical $63 \mathrm{t}$ capacity $567 \mathrm{~kW}$ truck, by relating total resistance to the engine speed-rimpull-gradeability curve, the effect of increases in rolling resistance (apparent as an equivalent increase in total resistance) can be seen. Figure 5 shows this effect, both for a typical flat haul ( $0 \%$ grade) and a decline haul (at $14 \%$ against the grade). As road rolling resistances increase on the flat haul, speeds reduce by over $36 \%$ (from 43 to $27 \mathrm{~km} / \mathrm{hr}$ ). Similarly, but less severely, the impact of rolling resistance on the decline is a loss of approximately $2 \mathrm{~km} / \mathrm{hr}$ from $10 \mathrm{~km} / \mathrm{hr}$ at $16 \%$ total resistance to $8 \mathrm{~km} / \mathrm{hr}$ at $19 \%$.

Speed reduction (percent reduction from max speed) with total resistance (grade + rolling resistance)

Typical $63 \mathrm{t}$ capacity truck $(567 \mathrm{~kW}) 45 \mathrm{~km} / \mathrm{h}$ top speed

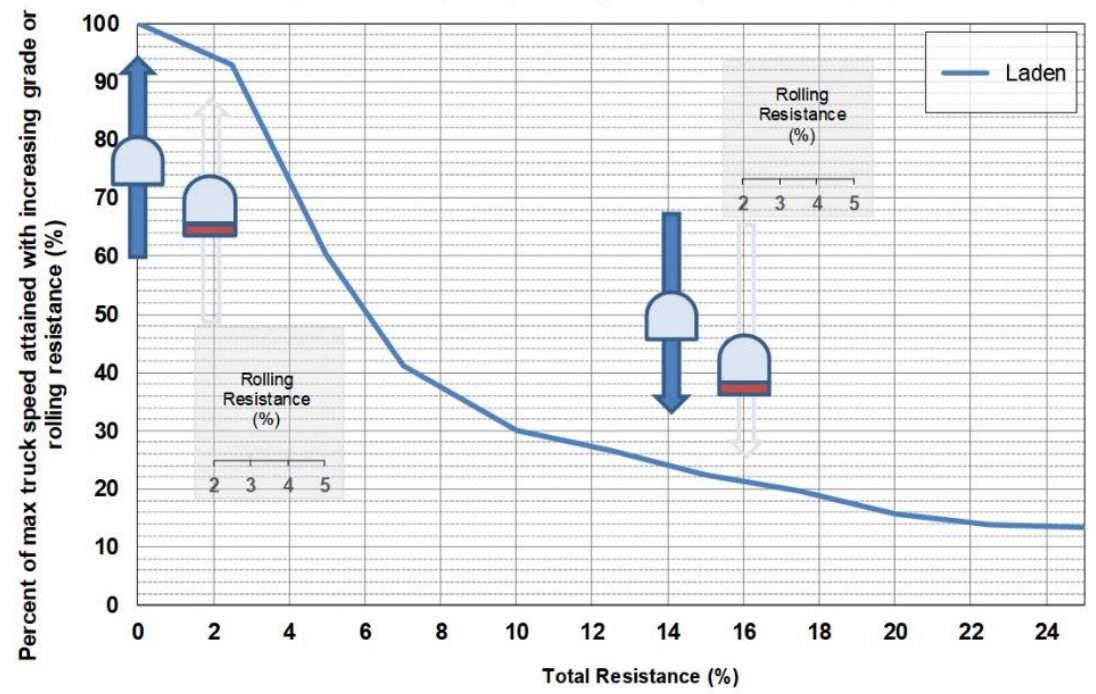

Figure 5 Speed reduction associated with rolling resistance and grade resistance - underground haul truck

Figure 6 illustrates the same concepts, but in this case for an LHD with a maximum speed of $24 \mathrm{~km} / \mathrm{hr}$. When rolling resistance on the flat haul increases from 2 to $5 \%$, speed reduces from 21 to $13 \mathrm{~km} / \mathrm{hr}$. 
Fuel consumption increases with rolling resistance. Using the Cooper equations (Cooper 2008), fuel consumption can be estimated for the same underground truck depicted in Figure 5, using a fuel burn index of 1.00 representing fuel consumption (litres $/ \mathrm{km}$ ) at $1 \%$ total resistance. Figure 7 shows that as rolling resistance increases from 2 to $5 \%$, fuel burn increases by a factor of 2.8 (approximately from 1.9 to $4.8 \mathrm{~L} / \mathrm{km}$ for flat haul and 15.3 to $18.1 \mathrm{~L} / \mathrm{km}$ for a $14 \%$ grade, for the specific truck type modelled.

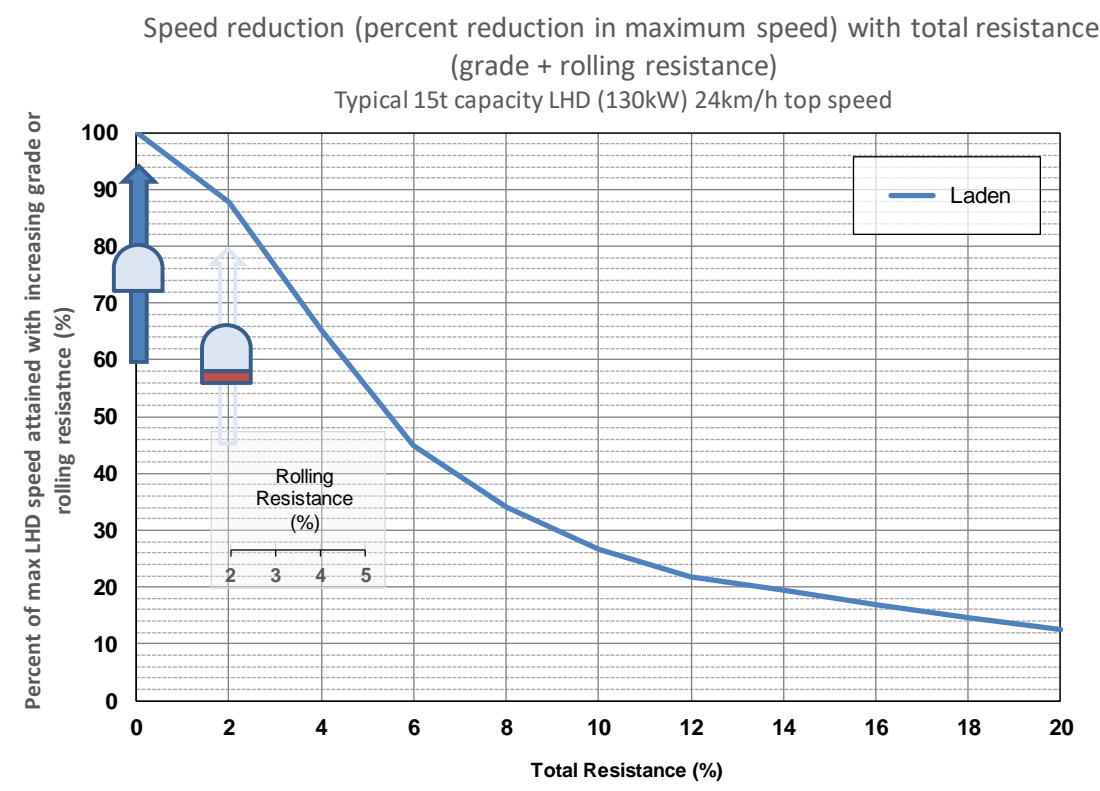

Figure 6 Speed reduction associated with rolling resistance and grade resistance - LHD

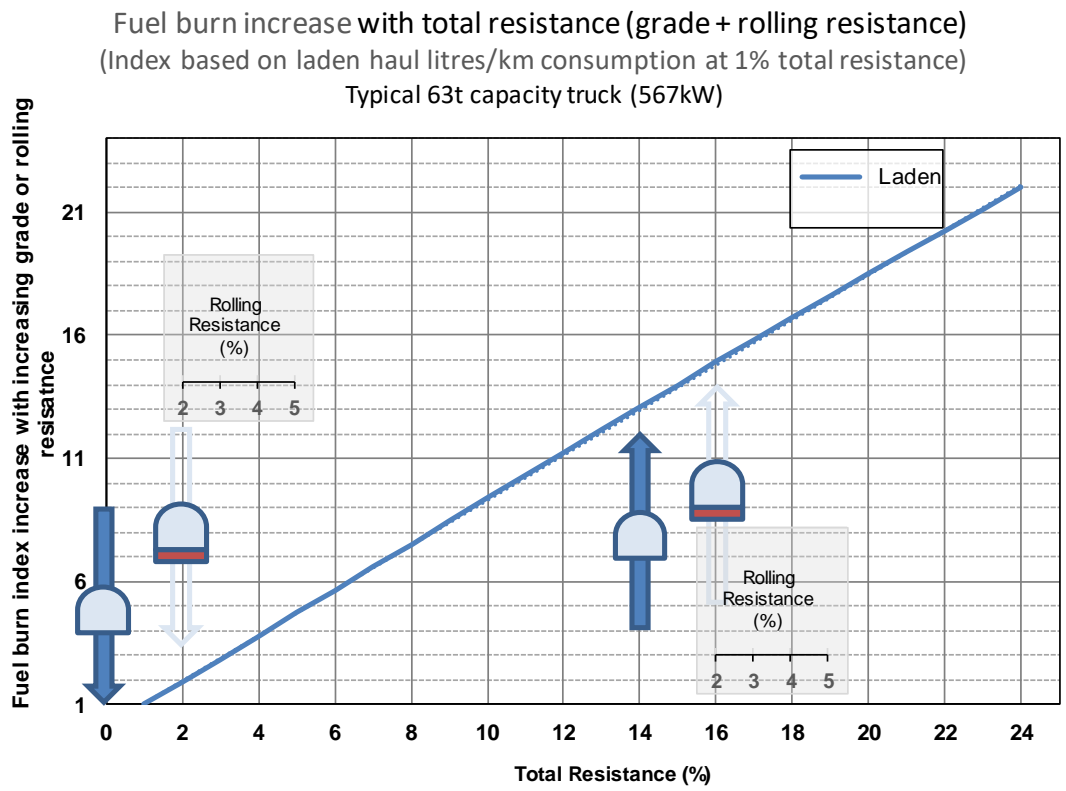

Figure 7 Fuel burn increase with rolling resistance and grade resistance - underground truck

In assessing the impacts of poor road design on productivity, it is important to firstly identify roadway issues and predict their impact on operations. Do these roadway issues need to be resolved now, in the next month or the next half year? To reliably answer that question, operations need to know more about their roadways and how they respond to the vehicles using them. Roads should be treated as an asset and designed and managed as such - when should they be maintained and how often, what is their operating life, etc. - to maintain optimal performance. In this case, since the geometrics of the haul cannot be easily altered post-design, optimal roadway performance is related to sustaining the lowest practical rolling resistance by designing roadways appropriate to traffic, materials and performance requirements. 
The value created by minimising rolling resistance can be found by considering each segment's haul profiles and the proportion of the cycle spent on that segment, together with traffic volumes. In all cases, the more heavily trafficked these segments are, the greater will be the benefit derived from appropriate design and reduced road maintenance interventions. Referring to Figure 5 , for a truck on a flat haul, when rolling resistance reaches $5 \%$, speed has reduced by $36 \%$ or $16 \mathrm{~km} / \mathrm{hr}$. On the decline, however, speed drops by only $2 \mathrm{~km} / \mathrm{hr}$ for the same increase in rolling resistance. Depending then on the specific haul profile, it is possible to determine where the effort should be invested in roadway design, improved materials or ongoing road maintenance.

\section{Design technology summary}

The mine road design methodology shown in Figure 2 forms the basis of the roadway design requirements and enhancements for high-volume bulk underground mining, in which AHS will become increasingly prevalent. Design and associated technologies need to mature at the same rate as AHS evolve. Construction practices and materials used in most mine roads will not provide adequate or predictable performance in the presence of high-volume and AHS operation. This situation will be aggravated if any of the design variables themselves (i.e. road geometry, vehicle speeds, vehicle wheel loadings, materials, etc.) depart further from what is known or experienced currently. To meet this challenge, in addition to ongoing problem solving, and 'tactical' developments in roadway design and management, some longer-term needs of a more strategic nature are evident:

- Improved assessment and documentation of 'as-built' conditions of the roadway, as a benchmark for design limits, failure mode determination and deterioration modelling.

- Assessment of concrete and unconventional and hybrid material options, both in terms of strength and the associated limiting design and performance criteria.

- Impact of highly channelised traffic on a constrained model of roadway structural and functional (abrasion resistance) performance.

- Real-time determination of road condition and defect/distress development and locations using either on-board or additional instrumentation.

- Analysis of roadway condition-triggered maintenance requirements and strategies in comparison to roadway design adopted.

- Development of a more rigorous understanding of mine roadway lifecycle costing and performance prediction techniques.

\section{Conclusion}

Underground roadways are an asset and should, in conjunction with the vehicles using them, be optimally designed and their routine maintenance predicted, planned and managed accordingly. Empirical approaches using unbound crushed rock in roadway design leads to excessive operating and road maintenance costs, together with premature failures with significant safety and productivity impacts. This has led to modern bulk mining and AHS operations adopting and developing other approaches including bituminous surfaces, high-strength ( $80 \mathrm{MPa}$ ) concrete and hybrid polymer stabilised and grouted solutions. These approaches address in particular the effects of roadway deterioration (especially potholing, rutting and tyre abrasion of the running surface), tyre wear, machine and operator fatigue and contribute to productivity, cost efficiency and, critically, safety improvements in both manual and autonomous systems.

Adopting design methodologies directly from other applications is not a fit-for-purpose solution due to the unique design requirements of mine roadways, more so in the case of autonomous systems where tight tolerances and a smooth and clean running surface is a prerequisite for successful implementation. A low- or no-maintenance roadway is the preferred option, and whilst technically feasible, given the short operating life of many roadways, economic justification on the basis of savings in road maintenance alone can be problematic. Ideally, a cost-optimisation approach should be adopted where the value invested in the 
roadway is offset against the costs of lost production, equipment shutdowns, road maintenance requirements and the associated increase in unit operating costs. All roadways will deteriorate over time and under the action of traffic, and as road rolling resistance increases, haul speeds can reduce by as much as $36 \%$ on the flat and $20 \%$ on grade. Similarly, there is a fuel consumption penalty too - fuel burn increasing by a factor of 2.8 as rolling resistance increases from 2 to $5 \%$.

Of the four design activities associated with roadway design, the geometric component is the best established in terms of road user requirements, but often requires compromise. The remaining three aspects; structural, functional and maintenance designs and associated technologies need to mature, especially in the case of construction practices and materials. Whilst a mechanistic design approach is useful in determining the extent to which a design satisfies a particular limiting criteria, it is nevertheless necessary to establish those design criteria with greater confidence when applied to mine roadways, vehicles and especially the hybrid treated and stabilised materials now available. From the functional perspective, minimising maintenance interventions and reducing abrasive wear is a paramount consideration, and more effort is required to better understand the process of wear at the tyre and road interface, together with solutions developed specifically for that location, as opposed to treating the full width of the roadway.

Key areas of focus required to supplement the existing roadway design knowledge are both short-term tactical and longer-term, covering improved assessment and documentation of roadways, as a benchmark for determining realistic and appropriate design limits and failure mode modelling. This should be coupled with the assessment of unconventional and hybrid materials options, and a more rigorous understanding of mine roadway lifecycle costing and performance prediction techniques.

\section{Acknowledgement}

Acknowledgement is given to Mining3 for support under project 2017-35 'Improving roadway resilience and trafficability - supporting high-volume, high-efficiency and autonomous hauling'.

\section{References}

Asphalt Institute 2013, 'Paving to the centre of the earth', Asphalt, viewed 20 April 2018, http://asphaltmagazine.com/paving-to-thecenter-of-the-earth

Carrick, K, McLean, M \& Davidson, JK n.d., Use of Asphalt Emulsions in Underground Mines, McAsphalt Industries Limited, Toronto, viewed 20 April 2018, http://www.mcasphalt.com/learning-centrelibrary

Caterpillar n.d., 'Asphalt reclamation paves way for efficient underground haulage', Viewpoint Magazine, no. 2, viewed 9 April 2018, http://viewpointmining.com/article/asphalt-reclamation-paves-way-for-efficient-underground-haulage

Cooper, A 2008, Modelling Truck Performance in a Spreadsheet, internal document, Snowden Mining Consultants, Perth.

Department of Transport 1996, TRH4 (1996) Flexible Pavement Design, viewed 12 January 2018, available at http://www.nra.co.za

ITW Engineered Polymers 2018, Technical Data Sheet - Densiphalt, viewed 25 July 2018, http://densit.com/media/27253/prodensiphalt-uk.pdf

Pidwerbesky, B 2004, 'AustRoads pavement design', Mechanistic Design and Evaluation of Pavements 2004 Workshop, viewed 12 January 2018, http://www.pavementanalysis.com/index.php/research-menu/research-seminars-menu

Seedsman, R, Logan, A, Cocks, G \& Nicholls, B 1994, Underground Roads Manual: Construction and Maintenance, Australian Coal Associated Research Program, Queensland.

Soil Solutions 2018, Engineered Base Stabiliser (EBS), viewed 21 April 2018, https://www.soilsolutions.com/ebs-soil-stabilizer

Theyse, HL, De Beer, M \& Rust, F 1996, 'Overview of the South African mechanistic pavement design analysis method', Transportation Research Record, vol. 1539, pp. 6-17, https://dx.doi.org/10.3141/1539-02

Thompson, RJ 2011, 'Design, construction and management of haul roads', in P Darling (ed.), SME Mining Engineering Handbook, Society for Mining, Metallurgy and Exploration, Englewood, pp. 957-976.

Thompson, RJ \& Visser, AT 1996, 'Towards a mechanistic structural design method for surface mine haul roads', Journal of the South African Institution of Civil Engineers, vol. 38, no. 2, pp. 13-21.

Thompson, RJ \& Visser, AT 2006, 'Selection and maintenance of mine haul road wearing course materials', Transactions of the Institutions of Mining and Metallurgy: Section A, vol. 115, no. 4, pp. 140-153.

Wolfgang, R \& Burgess-Limerick, R 2014, 'Whole-body vibration exposure of haul truck drivers at a surface coal mine', Applied Ergonomics, vol. 45, no. 6, pp. 1700-1704, https://dx.doi.org/10.1016/j.apergo.2014.05.020

Yoder, EJ \& Witczak, MW 1975, Principles of Pavement Design, 2nd edn, John Wiley \& Sons, New York. 